\title{
GANHO DE PRODUTIVIDADE PELO MELHORAMENTO GENÉTICO DO ARROZ IRRIGADO NO NORDESTE DO BRASIL ${ }^{1}$
}

\author{
FLÁVIO BRESEGHELLO², PAULO HIDEO NAKANO RANGEL e ORLANDO PEIXOTO DE MORAIS ${ }^{3}$
}

\begin{abstract}
RESUMO - Os ganhos genéticos para produtividade obtidos pelo programa de melhoramento do arroz irrigado por inundação na Região Nordeste do Brasil no período de 1984 a 1993 foram estimados visando avaliar a eficiência do programa e traçar novas estratégias. Esta estimativa foi feita a partir dos dados de 59 ensaios regionais de rendimento conduzidos pelas empresas de pesquisa agropecuária do Nordeste, em cooperação com a Embrapa-Centro Nacional de Pesquisa de Arroz e Feijão (CNPAF), Goiânia, GO. O método estatístico utilizado baseia-se em médias ajustadas por modelo linear generalizado. O ganho genético médio estimado foi de $54,9 \pm 14,4 \mathrm{~kg} / \mathrm{ha} / \mathrm{ano}(0,8 \%)$. Nos últimos três anos houve uma tendência de interrupção dos ganhos. A pequena magnitude dos ganhos para produção nesta região podem ser atribuídos ao direcionamento do programa de geração de linhagens da Embrapa para qualidade de grãos e resistência a doenças, às diferenças ambientais existentes entre Goiânia e a Região Nordeste e ao pequeno número de ensaios conduzidos. A genealogia das linhagens foi traçada e verificou-se que os principais ancestrais são os mesmos das cultivares recomendadas. A base genética das linhagens é estreita, o que também pode estar contribuindo para a obtenção de pequenos ganhos genéticos para produtividade.
\end{abstract}

Termos para indexação: ganho genético, base genética, programa de melhoramento.

YIELD GAIN THROUGH IRRIGATED RICE BREEDING IN THE NORTHEAST BRAZIL

\begin{abstract}
The genetic gains for yield obtained by the breeding program of irrigated rice in the Northeast Region of Brazil from 1984 to 1993 were estimated to evaluate the program efficiency. This estimation was done based on data from 59 regional field trials conducted by the Northeastern farm research institutions in cooperation with Embrapa-Centro Nacional de Pesquisa de Arroz e Feijão (CNPAF), Goiânia, GO, Brazil. The statistical method used was based on adjusted means by generalized linear model. The estimated mean genetic gain was $54.9 \pm 14.4 \mathrm{~kg} / \mathrm{ha}^{-1} / \mathrm{yr}^{-1}(0,8 \%)$. However, in the last three years, there was a tendency of interrupting the gains. The small gain obtained for yield in the referred region may be attributed to the strategy adopted by the line breeding program of Embrapa, which has priority for grain quality and disease resistance, the environmental differences between Goiânia and the Northeast Region and the small number of trials conducted. The genealogy of the lines was traced back and it was identified that the main ancestors are mostly the same as the released varieties. The genetic base of the lines is narrow, which may be contributing to the small genetic gains obtained for yield.
\end{abstract}

Index terms: genetic gain, genetic base, breeding program.

\footnotetext{
${ }^{1}$ Aceito para publicação em 23 de julho de 1998.

Extraído da Tese de Mestrado apresentada pelo primeiro autor à Universidade Federal de Goiás, Goiânia, GO.

${ }^{2}$ Eng. Agr., M.Sc., Embrapa-Centro Nacional de Pesquisa de Arroz e Feijão (CNPAF), Caixa Postal 179, CEP 75375-000 Santo Antônio de Goiás, GO. E-mail: cnpaf@networld.com.br ${ }^{3}$ Eng. Agr., Dr., Embrapa-CNPAF.
}

\section{INTRODUÇÃO}

A cultura do arroz irrigado na Região Nordeste do Brasil é promissora, devido ao grande mercado consumidor e às condições climáticas favoráveis. $O$ clima quente durante o ano todo possibilita a obtenção de duas safras por ano. Na zona de clima 
semi-árido as doenças fúngicas, inclusive a brusone, não encontram condições favoráveis para se desenvolverem. Nestas mesmas regiões a agricultura irrigada atua como um elemento fixador do homem à terra, contribuindo assim para reduzir o êxodo rural.

O melhoramento genético tem um papel essencial na viabilização dessa cultura, mediante o desenvolvimento de cultivares adaptadas para a região. Este trabalho, como qualquer outra atividade econômica, deve ser bem administrado, para que cada unidade de recurso investido resulte no máximo ganho possível. A administração de um programa de melhoramento de plantas anuais exige que se conheçam os resultados obtidos a cada ano em conseqüência dos métodos empregados. Esta informação é de suma importância para a avaliação da sua eficiência e assim definir quais estratégias serão adotadas para maximizar as chances de sucesso.

As instituições de pesquisa agropecuária da Região Nordeste, em cooperação com a Embrapa-Centro Nacional de Pesquisa de Arroz e Feijão (CNPAF) conduzem ensaios em rede, nos quais são avaliadas as melhores linhagens disponíveis em cada ano, com o fim de recomendar novas cultivares. Vencovsky et al. (1988) demonstraram que é possível que os dados destes ensaios sejam utilizados para a estimação dos ganhos genéticos para produtividade. Quando estes dados forem desbalanceados, no entanto, a análise de variância deve ser feita usando modelos lineares generalizados, como em Breseghello (1995).

Alguns trabalhos foram realizados anteriormente, visando estimar o ganho genético proporcionado pelo melhoramento. Abbud (1991) estimou um ganho de produtividade do arroz de sequeiro no Paraná em 1,3\% ao ano, no período de 1975/76 a 1988/89. Em Minas Gerais, no período de 1979 a 1988, Soares (1992) estimou o progresso genético do arroz irrigado em 1,6\% ao ano, enquanto que o arroz de sequeiro ganhou em média 3,0\% ao ano. Para efeito de comparação, o melhoramento de soja resultou em ganhos anuais de $1,3 \%$ a 1,8\%, no Paraná, no período de 1981 a 1986 (Toledo et al., 1990). O sorgo aumentou a produtividade, em média, 1,5\% ao ano, no período de 1974 a 1988 (Rodrigues, 1990). Em Minas Gerais, segundo estudo de Abreu et al. (1992), os novos genótipos de feijão representaram um avanço de $1,9 \%$ ao ano em relação à Carioca, que é a cultivar mais plantada naquele Estado.
Outro componente do melhoramento de que o pesquisador não deve descuidar-se é a base genética das linhagens que estão sendo produzidas pelo seu programa. Um número aparentemente grande de linhagens pode representar um tamanho efetivo populacional restrito, quando estas linhagens são muito aparentadas (Morais, 1997). Além disso, a semelhança genética entre cultivares de qualquer cultura é um fator de risco em relação aos estresses bióticos, principalmente doenças.

O objetivo deste trabalho foi avaliar a eficiência do melhoramento genético do arroz irrigado por inundação na Região Nordeste do Brasil, quanto à produtividade (no período de 1984 a 1993), e determinar a base genética das linhagens avaliadas, visando identificar os fatores limitantes do ganho e delinear estratégias para os trabalhos futuros nesta área.

\section{MATERIAL E MÉTODOS}

Os dados utilizados neste trabalho foram obtidos de 59 ensaios finais de rendimento, designados, no projeto de pesquisa em execução, de Ensaios Comparativos Avançados de linhagens de arroz irrigado por inundação, conduzidos pelas instituições de pesquisa agropecuária da Região Nordeste do Brasil, no período de 1984 a 1993 (Tabela 1). O delineamento experimental utilizado foi o de blocos casualizados, tendo sido 49 ensaios com quatro repetições e dez com três repetições. Utilizaram-se apenas ensaios com coeficiente de variação para produção menor que $20 \%$. As linhagens avaliadas são procedentes do projeto de melhoramento de arroz irrigado coordenado pela Embrapa-CNPAF. As testemunhas-padrão utilizadas foram Metica 1 e Cica 8.

Os genótipos avaliados em 1985 e 1986 foram os mesmos. Para evitar colinearidade nas matrizes utilizadas para o cálculo do ganho genético, os dois anos foram considerados como sendo apenas um, e os resultados finais foram corrigidos considerando-se a duração real do período.

Os dados disponíveis para a Região Nordeste são desbalanceados, pois por englobar vários Estados, alguns genótipos não foram avaliados em todos os locais dentro de ano. A análise de variância foi feita, portanto, segundo modelo linear generalizado, utilizando o procedimento GLM do pacote estatístico SAS (SAS Institute, 1985) e foram estimadas as médias ajustadas, para efeito de anos e de ensaios dentro de anos. 
TABELA 1. Locais onde foram conduzidos os Ensaios Comparativos Avançados de arroz irrigado, cujos dados foram utilizados para o cálculo do ganho genético para a Região Nordeste, empresa de pesquisa responsável pelo ensaio e número de ensaios por local e por ano.

\begin{tabular}{|c|c|c|c|c|c|c|c|c|c|c|c|c|c|}
\hline \multirow[t]{2}{*}{ Município } & \multirow[t]{2}{*}{ Estado } & \multirow{2}{*}{$\begin{array}{l}\text { Empresa } \\
\text { de pesquisa }\end{array}$} & \multicolumn{10}{|c|}{ Ano } & \multirow{2}{*}{$\begin{array}{l}\text { Ensaios } \\
\text { por local }\end{array}$} \\
\hline & & & 84 & 85 & 86 & 87 & 88 & 89 & 90 & 91 & 92 & 93 & \\
\hline Arari & MA & EMAPA & 1 & 1 & 1 & 1 & 1 & & 1 & & & & 6 \\
\hline Teresina & PI & UEPAE & 1 & 1 & 1 & 1 & 1 & & 1 & 1 & 1 & 1 & 9 \\
\hline Eliseu Martins & PI & UEPAE & & 1 & & & & & & & & & 1 \\
\hline Miguel Alves & PI & UEPAE & & & & & & & & 1 & 1 & & 2 \\
\hline Buriti dos Lopes & PI & UEPAE & & & 1 & & & & & & & & 1 \\
\hline Parnaíba & PI & CPAMN & & & & 1 & & 1 & 2 & 2 & & 1 & 7 \\
\hline Barbalha & $\mathrm{CE}$ & EPACE & & & & 2 & 1 & & & 1 & & & 4 \\
\hline Iguatu & $\mathrm{CE}$ & EPACE & & & & & & & & 1 & & & 1 \\
\hline Icó & $\mathrm{CE}$ & EPACE & & & & & & & & & & 1 & 1 \\
\hline Morada Nova & $\mathrm{CE}$ & EPACE & & & & & & & & & & 1 & 1 \\
\hline Ipanguaçu & $\mathrm{RN}$ & EMPARN & & 1 & & 1 & 1 & 1 & 2 & & & & 6 \\
\hline Caicó & RN & EMPARN & & & & & & 1 & 1 & & & & 2 \\
\hline São Gonçalo & $\mathrm{PB}$ & EMEPA & & & & & 1 & & & & & & 1 \\
\hline Cabrobó & $\mathrm{PE}$ & IPA & & & & 1 & 1 & & 1 & & 1 & & 4 \\
\hline Belém S. Francisco & $\mathrm{PE}$ & IPA & & & & & 1 & 2 & & & 2 & 1 & 6 \\
\hline Penedo & $\mathrm{AL}$ & EPEAL & 1 & 1 & & 1 & 1 & & & & 1 & 2 & 7 \\
\hline Ensaios por ano & & & 3 & 5 & 3 & 8 & 8 & 5 & 8 & 6 & 6 & 7 & 59 \\
\hline
\end{tabular}

A matriz de covariância do vetor de médias dos genótipos, ajustadas para efeito de ano e de ensaio/ano, foi estimada por:

$\hat{\mathrm{V}}(\hat{\mathrm{Y}})=\mathrm{C}\left(\mathrm{X}^{\prime} \mathrm{X}\right) \mathrm{C}^{\prime} \mathrm{QMR}$ esíduo

sendo:

C: matriz de coeficientes das soluções do modelo, tal que $\hat{\mathrm{Y}}=\mathrm{C} \theta^{\circ}$ (conjunto de funções estimáveis), sendo $\theta^{\circ} \mathrm{o}$ vetor de soluções de quadrados mínimos do modelo utilizado

$\left(\mathrm{X}^{\prime} \mathrm{X}\right)^{-}$: inversa generalizada da matriz $\mathrm{X}^{\prime} \mathrm{X}$, fornecida pelo procedimento GLM do SAS. X é a matriz de coeficientes dos parâmetros do modelo;

$\mathrm{QMR}_{\text {esíduo: }}$ é o estimador do quadrado médio residual da análise de variância.

No cálculo do ganho genético foi utilizado o método proposto por Breseghello (1995), que leva em consideração a produtividade média das linhagens avaliadas em um determinado ano, estimada com base em todas as observações disponíveis, não apenas naquelas realizadas no ano específico. O ganho genético médio obtido por este méto- do é ponderado, o que conferiu maior consistência à estimativa.

Sendo $Y_{\mathrm{i}}$ a média do genótipo i ajustada para anos e ensaios dentro de anos, e sendo $\mathrm{Y}_{\mathrm{k}}{ }^{*}$ a média aritmética das médias $Y_{i}$ dos genótipos avaliados no ano $\mathrm{k}$, as médias $\mathrm{Y}_{\mathrm{k}}$ * representam a produtividade média do grupo dos genótipos avaliados no ano $\mathrm{k}$, mas recuperando informações corrigidas disponíveis em outros anos para alguns genótipos do grupo.

Foi feita a regressão linear das médias $\mathrm{Y}_{\mathrm{k}}{ }^{*}$ para os anos $\mathrm{k}$, ponderada pela matriz de covariâncias das médias $\mathrm{Y}_{\mathrm{k}}{ }^{*}$, pelo método de quadrados mínimos generalizado, obtendo-se a estimativa ponderada de ganho genético médio, representada pelo coeficiente angular da reta.

A partir dos registros de cruzamentos do Centro Internacional de Agricultura Tropical (Martínez \& CuevasPérez, 1995), da Red Internacional para la Evaluación Genética del Arroz (1991) e do International Rice Research Institute (1985), foram traçadas as genealogias das linhagens avaliadas, identificando os principais ancestrais e calculando as respectivas contribuições genéticas relativas para a formação da base genética do conjunto de linhagens, conforme Rangel et al. (1996). 


\section{RESULTADOS E DISCUSSÃO}

\section{Ganhos genéticos}

Nos anos de 1985 e 1989 ocorreram os maiores ganhos genéticos, de $2,5 \%$ e $2,1 \%$ respectivamente (Tabela 2). A regressão ponderada da produtividade em relação aos anos resultou em um ganho genético médio de 54,9 $\pm 14,4 \mathrm{~kg} / \mathrm{ha} / \mathrm{ano}$, que corresponde a $0,8 \%$ da média ajustada do primeiro ano do período, que foi de $6.868 \mathrm{~kg} / \mathrm{ha}$. O coeficiente de determinação da regressão linear, significativo $\left(\mathrm{r}^{2}=0,66 ; \mathrm{P}<1 \%\right)$ indica que os ganhos de produtividade, em conseqüência do melhoramento, ajustam-se aproximadamente a uma reta. Analisandose a variação anual da produtividade média, no entanto, percebe-se que nos três últimos anos do período estudado ocorreu certa estagnação, com ganhos negativos, não significativos. Como pode ser visto na Tabela 3, de 1990 a 1992, esta estagnação é explicada pela não introdução de novas linhagens. Em 1993, o conjunto de linhagens avaliadas foi drasticamente renovado; contudo, isso não se traduziu em aumento da produtividade, pois as linhagens introduzidas tinham como vantagem principal a qualidade de grãos.

O ganho genético médio de produtividade obtido neste trabalho foi inferior aos estimados para outras regiões, por outros autores. Em relação a tal fato, algumas justificativas podem ser apresentadas:

1) A estimativa do presente trabalho foi obtida por meio de uma nova metodologia, diferente daquelas empregadas nos trabalhos anteriores; portanto, a comparação direta dos resultados deve ser analisada com reservas. Seria necessário um estudo da coerência entre os métodos, para que a comparação fosse mais exata.

2) O período estudado é posterior à fase de substituição das cultivares tradicionais pelas modernas linhagens semi-anãs. Quando ocorreu a substituição, houve um grande salto de produtividade. Depois disto, os ganhos relativos a este caráter têm sido modestos no Brasil (Rangel et al., 1992), assim como em todo o mundo (International Rice Research Institute, 1989).

3) O mercado de arroz no Brasil está se tornando mais exigente, o que faz com que os produtores obtenham maior rentabilidade com cultivares de alta qualidade de grãos, ainda que não sejam as mais produtivas entre as disponíveis. Em resposta a esta exigência, o melhoramento genético foi direcionado para a obtenção de cultivares com uma melhor qualidade de grãos. Grandes ganhos têm sido obtidos neste aspecto, mas isto representa também um estreitamento acentuado das possibilidades de obtenção de maiores produtividades, uma vez que

TABELA 2. Número de ensaios avançados utilizados, número de genótipos avaliados (linhagens e testemunhas), média aritmética das médias ajustadas dos genótipos, e ganho genético pelo melhoramento de arroz irrigado na Região Nordeste do Brasil.

\begin{tabular}{cccccc}
\hline Ano & $\begin{array}{c}\mathrm{N}^{\mathrm{o}} \text { ensaios } \\
\text { utilizados }\end{array}$ & $\begin{array}{c}\mathrm{N}^{\mathrm{o}} \text { genótipos } \\
\text { avaliados }\end{array}$ & $\begin{array}{c}\text { Média ajustada } \\
\mathrm{Y}_{\mathrm{k}}^{*}\end{array}$ & \multicolumn{2}{c}{ Ganho genético } \\
\cline { 2 - 6 } $\mathrm{kg} / \mathrm{ha}$ & - & - \\
84 & 3 & 14 & 6868 & $181 \pm 75$ & 2,6 \\
85 & 5 & 13 & 7049 & 0 & 0 \\
86 & 3 & 13 & 7049 & $-44 \pm 57$ & n.s. \\
87 & 8 & 13 & 7005 & $146 \pm 50$ & n.s. \\
88 & 8 & 21 & 7065 & $33 \pm 38$ & n.s. \\
89 & 5 & 23 & 7211 & $-8 \pm 40$ & n.s. \\
90 & 8 & 32 & 7236 & $-35 \pm 19$ & n.s. \\
91 & 6 & 22 & 7201 & $-40 \pm 116$ & n.s. \\
92 & 6 & 21 & 7161 & $54,9 \pm 14,4$ \\
\hline
\end{tabular}

${ }^{1}$ Estimativa de ganho genético não significativa. 
TABELA3. Linhagens avaliadas na Região Nordeste no período de 1984 a 1993, produtividades médias ajustadas por ano $\left(\mathrm{Y}_{\mathrm{i} / \mathrm{k}}\right)$ e ajustadas para todo o período $\left(\mathrm{Y}_{\mathrm{i}}\right)$ com os respectivos desvios padrões.

\begin{tabular}{|c|c|c|c|c|c|c|c|c|c|c|}
\hline \multirow[t]{2}{*}{ Genótipo } & \multicolumn{9}{|c|}{$Y_{i / k}$} & \multirow[t]{2}{*}{$\mathrm{Y}_{\mathrm{i}}$} \\
\hline & 84 & $85186^{1}$ & 87 & 88 & 89 & 90 & 91 & 92 & 93 & \\
\hline Metica 1 & 7169 & 7156 & 8105 & 7778 & 7981 & 7891 & 7127 & 8273 & 7554 & $7670+96$ \\
\hline Cica 8 & 7483 & 6307 & 7154 & 7531 & 7351 & 7914 & 7172 & 8112 & 7224 & $7300 \pm 97$ \\
\hline CNA 3459 & & & & 8066 & & 7465 & 6979 & 7770 & & $7353 \pm 163$ \\
\hline CNA 3739 & 6255 & 6205 & 6549 & 7636 & & 7535 & 6461 & 8618 & & $7050 \pm 118$ \\
\hline CNA 3743 & & & & & 8465 & 8701 & & & & $8207 \pm 264$ \\
\hline CNA 3760 & 6750 & 6417 & & & & & & & & $7262 \pm 232$ \\
\hline CNA 3762 & & & 7791 & 8206 & 7955 & 7322 & 6255 & 8153 & 7923 & $7638 \pm 168$ \\
\hline CNA 3771 & 6671 & 6368 & 7255 & 7873 & 7752 & 8253 & 6988 & 8212 & & $7406 \pm 116$ \\
\hline CNA 3815 & & 5424 & 7028 & 7845 & 7939 & 7706 & 6295 & 6742 & & $7052 \pm 133$ \\
\hline CNA 3852 & 5738 & 6023 & 6501 & 7319 & & 6838 & & & & $6647 \pm 141$ \\
\hline CNA 3879 & 6448 & 6064 & 6974 & 7188 & & 7057 & 6501 & 6659 & 6849 & $6734 \pm 115$ \\
\hline CNA 3887 & & 5257 & 7300 & 7887 & 7857 & 7539 & 7188 & 8101 & & $7337 \pm 122$ \\
\hline CNA 3888 & & & & & & 7869 & 6721 & 8883 & & $7676 \pm 191$ \\
\hline CNA 3889 & & & & 7914 & & & & & & $7389 \pm 425$ \\
\hline CNA 3891 & & & 7288 & 7551 & 7685 & 7859 & 6868 & & & $7297 \pm 136$ \\
\hline CNA 3922 & 6014 & & & & & & & & & $6507 \pm 436$ \\
\hline CNA 3924 & 6868 & 5952 & & & & & & & & $6956 \pm 257$ \\
\hline CNA 3947 & 5540 & & & & & & & & & $6033 \pm 436$ \\
\hline CNA 3949 & 6514 & 6724 & 7146 & 7904 & 6747 & & & & & $7284 \pm 144$ \\
\hline CNA 3950 & 5981 & 6153 & & & & & & & & $6780 \pm 315$ \\
\hline CNA 3952 & 6403 & 6251 & & & & & & & & $7031 \pm 291$ \\
\hline CNA 3955 & 6209 & & & & & & & & & $6734 \pm 745$ \\
\hline CNA 4081 & & & 5295 & 6903 & & & & & & $5818 \pm 207$ \\
\hline CNA 4212 & & & & & 6579 & & & & & $6380 \pm 525$ \\
\hline CNA 4223 & & & 6653 & 7377 & 7119 & 7110 & & & & $6795 \pm 172$ \\
\hline CNA 4892 & & & & & 8244 & 7568 & & & & $7560 \pm 334$ \\
\hline CNA 4893 & & & & 7529 & 7223 & 6861 & 6063 & 7458 & & $6748 \pm 151$ \\
\hline CNA 4897 & & & & 8406 & 7052 & 7858 & & 6967 & & $7163 \pm 194$ \\
\hline CNA 4898 & & & & & 7080 & 8262 & & & & $7065 \pm 282$ \\
\hline CNA 4899 & & & & 7772 & 7636 & 7413 & 6506 & 8589 & 7187 & $7272 \pm 123$ \\
\hline CNA 4954 & & & & & 7040 & 7695 & & & & $6874 \pm 282$ \\
\hline CNA 4968 & & & & & 7865 & 6587 & & & & $6808 \pm 373$ \\
\hline CNA 5058 & & & & 6864 & 7661 & 7703 & & & & $6868 \pm 281$ \\
\hline CNA 5191 & & & & 7773 & 8062 & 7620 & 6300 & 7408 & & $7100 \pm 142$ \\
\hline CNA 5247 & & & & & & 7316 & 5821 & 6968 & & $6507 \pm 205$ \\
\hline CNA 5259 & & & & & & & & & 7142 & $7156 \pm 380$ \\
\hline CNA 5383 & & & & & 7407 & 7163 & 6547 & 8824 & & $7262 \pm 170$ \\
\hline CNA 5387 & & & & & & 7448 & 6509 & 7911 & & $7114 \pm 198$ \\
\hline CNA 5394 & & & & 7667 & 7650 & 7565 & 6575 & 8465 & & $7284 \pm 137$ \\
\hline CNA 5544 & & & & & & 7396 & 6845 & 9058 & 7499 & $7641 \pm 167$ \\
\hline CNA 5683 & & & & & 8288 & 8711 & & & & $8043 \pm 334$ \\
\hline CNA 5719 & & & & & & 7425 & 7100 & 7928 & 7573 & $7365 \pm 156$ \\
\hline CNA 5743 & & & & & & 8129 & 7115 & & & $7754 \pm 348$ \\
\hline CNA 6082 & & & & & & & & & 7312 & $7331 \pm 294$ \\
\hline CNA 6083 & & & & & & 8040 & & & & $7712 \pm 426$ \\
\hline CNA 6309 & & & & & & & 6710 & 7705 & & $7122 \pm 329$ \\
\hline CNA 6363 & & & & & & & & & 7977 & $8002 \pm 530$ \\
\hline CNA 7183 & & & & & & & & & 5998 & $6024 \pm 530$ \\
\hline CNA 7216 & & & & & & & & & 7043 & $7062 \pm 294$ \\
\hline CNA 7218 & & & & & & & & & 6505 & $6521 \pm 342$ \\
\hline CNA 7222 & & & & & & & & & 7539 & $7558 \pm 294$ \\
\hline CNA 7232 & & & & & & & & & 7119 & $7138 \pm 294$ \\
\hline CNA 7241 & & & & & & & & & 6304 & $6329 \pm 530$ \\
\hline CNA 7251 & & & & & & & & & 7127 & $7152 \pm 530$ \\
\hline CNA 7257 & & & & & & & & & 6576 & $6595 \pm 294$ \\
\hline CNA 7259 & & & & & & & & & 6325 & $6344 \pm 294$ \\
\hline CNA 7262 & & & & & & & & & 7860 & $7886 \pm 530$ \\
\hline CNA 7263 & & & & & & & & & 7500 & $7519 \pm 294$ \\
\hline CNA 7264 & & & & & & & & & 7266 & $7285 \pm 294$ \\
\hline CNA 7266 & & & & & & & & & 7469 & $7488 \pm 294$ \\
\hline CNA 7268 & & & & & & & & & 7553 & $7572 \pm 294$ \\
\hline CNA 7269 & & & & & & & & & 7071 & $7090 \pm 294$ \\
\hline
\end{tabular}

${ }^{1}$ As linhagens avaliadas nos dois anos foram as mesmas. 
tais características são inversamente correlacionadas (Akita, 1995).

4) Deve ser considerado também que a seleção durante as gerações segregantes na Embrapa-CNPAF não priorizou o desenvolvimento de linhagens para as condições ambientais específicas do Nordeste, mas as das Regiões Central e Sul do País. Por este motivo, a probabilidade de obtenção de linhagens adaptadas à Região Nordeste foi reduzida. Isto fez com que a oferta de linhagens promissoras para a região do semi-árido não fosse muito grande. Por exemplo, linhagens de ciclo curto, que se adaptam bem no Sul, tornam-se superprecoces e pouco produtivas em baixas latitudes.

Lopes (1994) preconiza que, para aumentar a eficiência na obtenção de cultivares de arroz para a Região Nordeste, seria importante selecionar as populações segregantes na própria região. Esta estratégia poderia resultar em cultivares adaptadas àquelas condições ambientais específicas. A brusone, por exemplo, não apresenta importância econômica no semi-árido nordestino, mas muitas populações promissoras são descartadas por suscetibilidade à doença em Goiânia, antes mesmo de serem avaliadas naquela região.

O método de melhoramento utilizado também pode ter contribuído para o baixo ganho genético obtido. As linhagens avaliadas no período foram obtidas pelo método genealógico, o qual tem-se mostrado pouco eficiente para a obtenção de cultivares mais produtivas. Este método leva à utilização de reduzidos tamanhos efetivos populacionais, o que causa o aumento da endogamia e a redução da variabilidade genética, principalmente dos caracteres quantitativos.

A utilização de métodos que aumentam a probabilidade de surgimento de recombinantes em locos ligados, como a seleção recorrente (Rangel \& Neves, 1997), deve proporcionar novos horizontes para o melhoramento de arroz, principalmente quanto à produtividade. Recombinando-se gerações iniciais, reduz-se a duração dos ciclos de melhoramento, permitindo que sejam usadas pressões de seleção mais moderadas e que se mantenha um alto nível de heterozigose na população. Desta forma, o afunilamento genético das populações manipuladas no melhoramento é bem mais suave e pode ser evita- do com eventuais introgressões de parentais divergentes. A presente intensificação dos trabalhos em seleção recorrente na Embrapa-CNPAF, com a fase de avaliação de progênies realizada também no Nordeste, deve resultar no aumento da oferta de linhagens promissoras para condições locais, pois surgem oportunidades para a extração de novas linhagens adequadas aos mais variados ambientes.

\section{Taxa de substituição dos genótipos nos ensaios}

As substituições dos genótipos avaliados nos ensaios deram-se de forma muito irregular (Tabela 3 ). Em média foram testados 5,3 genótipos novos por ano, sobre um número médio de 19,7 tratamentos, o que dá uma taxa média de substituição de $27,0 \%$ ao ano. Esta taxa é bem menor que as verificadas em Minas Gerais (Soares, 1992), de 46\% para arroz irrigado e de $44 \%$ para arroz de sequeiro. No melhoramento de milho no Brasil, foi relatada uma média de $61 \%$ de substituição anual (Vencovsky et al., 1988), e no melhoramento de sorgo, a média foi de 43\% (Rodrigues, 1990).

Entre as linhagens modernas, as diferenças de produtividade a serem detectadas são cada vez mais estreitas. A identificação de linhagens mais produtivas exige a aplicação rigorosa das técnicas experimentais e estatísticas. A rede de avaliação do Nordeste conduziu um número relativamente pequeno de ensaios, e alguns não alcançaram bom nível de precisão. Em conseqüência, os genótipos permaneceram por mais tempo nos ensaios, até que houvesse informações suficientes para sua eliminação ou recomendação como cultivar, resultando, por fim, na avaliação de um número pequeno de genótipos no período.

A intensificação dos ganhos para produtividade de arroz irrigado no Nordeste, sem prejuízo das outras características de importância econômica, dependerá da manutenção de uma rede de ensaios sistemática e com bom nível de precisão experimental. Será necessária a avaliação de um número maior de materiais, em ensaios de observação e preliminares (que antecedem os ensaios comparativos avançados), aumentando, assim, a chance de identificação de boas linhagens. A aceleração do ritmo das pesquisas dependerá de intensa colaboração entre as instituições engajadas no melhoramento de arroz irrigado. 


\section{Base genética das linhagens}

Três variedades ancestrais tiveram pesos superiores a $10 \%$ do conjunto gênico avaliado. São elas Dee Geo Woo Gen (DGWG), Cina, e Lati Sail (Tabela 4). Apenas os três ancestrais somados respondem por $35,0 \%$ do conjunto gênico das linhagens avaliadas. A IR8 foi a primeira cultivar melhorada com tipo de planta moderno, criada pelo IRRI (International Rice Research Institute, situado nas Filipinas), tendo sido obtida do cruzamento entre Peta (Cina/Lati Sail), e DGWG, que é o mutante natural no qual se originou a característica de planta semianã. A importância de DGWG, Cina e Lati Sail na composição das linhagens atuais se deve ao uso intenso da cultivar IR8 nos cruzamentos visando à obtenção de cultivares semi-anãs altamente produtivas.

A cultivar Tetep é uma importante fonte de resistência à brusone, tendo por isso um peso de $8,3 \%$ na composição das linhagens. A cultivar Tadukan foi utilizada com o mesmo objetivo, mas com menor freqüência, e por isso seu peso é de 4,7\% dos genes. Os ancestrais I Geo Tze, Mong Chin Vang A e Remadja participam com peso superior a 5\%. Tais materiais foram utilizados nos cruzamentos por se- rem cultivares tradicionais, bem adaptadas e produtivas. Remadja é uma introdução mais recente, portanto representa uma introdução de genes "novos" no conjunto gênico trabalhado.

Quanto à origem geográfica, verifica-se a predominância absoluta das variedades asiáticas. Entre os vinte ancestrais identificados, apenas cinco não são provenientes da Ásia, totalizando $6,1 \%$ do conjunto gênico das linhagens.

Cuevas-Pérez et al. (1992) construíram as árvores genealógicas das cultivares de arroz lançadas na América Latina e Caribe no período de 1971 a 1989, chegando a 101 ancestrais que formam a base genética de todas as cultivares melhoradas. $\mathrm{O}$ número pode ser considerado satisfatório, mas a importância relativa de cada um é muito desigual. DGWG, Cina e Lati Sail respondem por 39\% dos alelos, pouco mais do que foi encontrado no presente trabalho. Quando se considera a área plantada com cada cultivar, a importância dos ancestrais de IR8 sobe para $56 \%$, mostrando a grande adaptabilidade destes genes.

Comparando-se os resultados deste trabalho com estudos de Rangel et al. (1996), referentes à base genética das principais cultivares de arroz irrigado

TABELA 4. Principais ancestrais das linhagens avaliadas e sua contribuição genética relativa (CGR), contribuição genética relativa acumulada (CGRA) e origem geográfica.

\begin{tabular}{lccc}
\hline Ancestrais & CGR $(\%)$ & CGRA $(\%)$ & Origem \\
\hline Dee Geo Woo Gen & 12,9 & 12,9 & Taiwan \\
Cina & 11,0 & 23,9 & China \\
Lati Sail & 1,0 & 35,0 & Índia \\
Tetep & 8,3 & 43,3 & Vietnã \\
I Geo Tze & 5,6 & 48,8 & China \\
Mong Chin Vang A & 5,6 & 54,4 & Vietnã \\
Remadja & 5,3 & 59,6 & Sri Lanka \\
Tadukan & 4,7 & 64,4 & Filipinas \\
Taichung Native 1 & 1,8 & 66,2 & Taiwan \\
SML 56|7 & 1,8 & 68,0 & Suriname \\
Sigadis & 1,8 & 69,7 & Indonésia \\
Takao Iku 18 & 1,4 & 71,2 & China \\
Belle Patna & 1,3 & 72,4 & Eua \\
Costa Rica & 1,2 & 73,6 & Costa Rica \\
NMS 4 & 1,2 & 74,8 & Tailândia \\
Khao Dawk Mali 105 & 1,2 & 76,0 & Tailândia \\
CR 94-13 & 1,1 & 77,1 & Índia \\
CP-SLO & 1,1 & 78,2 & Eua \\
C 46-15 & 1,0 & 79,2 & Mianmar \\
63-83 & 0,8 & 80,0 & Senegal \\
Não identificado & 20,0 & 100,0 & - \\
\hline
\end{tabular}


do Brasil, verifica-se haver grande coincidência de ancestrais. Os seis ancestrais mais importantes aqui identificados são responsáveis pelo fornecimento de $71 \%$ dos alelos das lavouras de arroz irrigado do Brasil, considerando-se a área plantada com cada cultivar.

Os resultados indicam que as linhagens que estão sendo avaliadas nos ensaios finais têm a base genética muito semelhante à das cultivares atualmente recomendadas. Portanto, o lançamento de novas cultivares extraídas deste conjunto provavelmente acrescentaria pouco em diversidade genética no campo. Para obter maior diversidade, e, assim, maior segurança contra estresses bióticos, será necessário ampliar a base genética sobre a qual o melhoramento tem trabalhado, sem perder a adaptabilidade necessária para que as novas cultivares sejam adotadas pelos rizicultores.

\section{CONCLUSÕES}

1. O ganho genético, em produtividade, do arroz irrigado no Nordeste do Brasil, no período de 1984 a 1993, é considerado baixo.

2. O número de ensaios realizados no período é pequeno em relação à amplitude geográfica da região.

3. O baixo ganho genético obtido pode ser atribuído ao pequeno número de genótipos avaliados.

4. A base genética das linhagens avaliadas é semelhante à das cultivares em uso no mesmo período.

\section{AGRADECIMENTOS}

À Empresa Brasileira de Pesquisa Agropecuária (Embrapa), através do Centro de Pesquisa Agropecuária do Meio Norte (CPAMN), à Empresa Maranhense de Pesquisa Agropecuária (EMAPA), à Empresa de Pesquisa Agropecuária do Ceará (EPACE), à Empresa de Pesquisa Agropecuária do Rio Grande do Norte (EMPARN), à Empresa Pernambucana de Pesquisa Agropecuária (IPA), à Empresa de Pesquisa Agropecuária da Paraíba (EMEPA) e à Empresa de Pesquisa Agropecuária de Alagoas (EPEAL), por terem cedido os dados utilizados neste trabalho; ao Conselho Nacional de De- senvolvimento Científico e Tecnológico (CNPq), pela concessão da bolsa de estudo ao primeiro autor.

\section{REFERÊNCIAS}

ABBUD, N.S. Melhoramento genético do arroz de sequeiro (Oryza sativa L.) no Estado do Paraná de 1975 a 1989. Piracicaba: ESALQ, 1991. 141p. Tese de Doutorado.

ABREU, A. de F.B.; RAMALHO, M.A.P.; SANTOS, J.B.; MARTINS, L.A. Progresso do melhoramento genético do feijoeiro nas décadas de 70 e 80 nas regiões Sul e Alto Paranaíba, em Minas Gerais. Projeto Feijão: Relatório 88/92, Viçosa, 1992. p.118-122.

AKITA, S. Aspectos ecofisiológicos relacionados ao aumento do potencial de rendimento biológico e comercial da cultura do arroz (Oryza sativa L.). In: PINHEIRO, B.S.; GUIMARÃES, E.P. (Eds.). Arroz na América Latina: perspectivas para o incremento da produção e do potencial produtivo. Goiânia: Embrapa-CNPAF/APA, 1995. v.1, p.57-76. (Embrapa-CNPAF. Documentos, 60).

BRESEGHELLO, F. Ganhos para produtividade pelo melhoramento genético do arroz irrigado no Nordeste do Brasil. Goiânia: UFG, 1995. 93p. Tese de Mestrado.

CUEVAS-PÉREZ, F.E.; GUIMARÃES, E.P.; BERRÍO, L.E.; GONZÁLEZ, D.I. Genetic base of irrigated rice in Latin America and the Caribbean, 1971 to 1989. Crop Science, Madison, v.32, p.1054-1059, 1992.

INTERNATIONAL RICE RESEARCH INSTITUTE. Parentage of IRRI crosses IR1-IR50000. Manila, 1985. 1v.

INTERNATIONAL RICE RESEARCH INSTITUTE. IRRI 1989: planning for the 1990's. Manila, 1989. $72 \mathrm{p}$.

LOPES, A.M. Avaliação crítica dos projetos do PNP-Arroz na área de melhoramento genético, no período de 1980 a 1990: Regiões Norte e Nordeste. In: EMBRAPA. Centro Nacional de Pesquisa de Arroz e Feijão (Goiânia, GO). A pesquisa de arroz no 
Brasil nos anos 80: avaliação crítica dos principais resultados. Goiânia, 1994. p.287-307. (EmbrapaCNPAF. Documentos, 40).

MARTÍNEZ, C.P.; CUEVAS-PÉREZ, F.E. Registro de cruzamientos de arroz: P1-P5617 y CT5618-CT13800. Cali: CIAT, 1995. 313p.

MORAIS, O.P. Tamaño efectivo de la población. In: GUIMARÃES, E.P. (Ed.). Selección recurrente en arroz. Cali: CIAT, 1997. p.25-44. (Publicación CIAT, n.267).

RANGEL, P.H.N.; GUIMARÃES, E.P.; NEVES, P.C.F. Base genética das cultivares de arroz (Oryza sativa L.) irrigado do Brasil. Pesquisa Agropecuária Brasileira, Brasília, v.31, n.5, p.349-357, maio 1996.

RANGEL, P.H.N.; NEVES, P.C.F. Selección recurrente aplicada al arroz de riego en Brasil. In: GUIMARÃES, E.P. (Ed.). Selección recurrente en arroz. Cali: 1997. p.79-97. (Publicación CIAT, n.267).

RANGEL, P.H.N.; ZIMMERMANN, F.J.P.; NEVES, P.C.F. El CNPAF investiga: decresce en Brasil el rendimiento del arroz de riego? Arroz en las Américas, Cali, v.13, n.1, p.2-4, 1992.
RED INTERNACIONAL PARA LA EVALUACIÓN GENÉTICA DEL ARROZ. Cruzamientos de arroz: América Latina. Cali, 1991. v.1.

RODRIGUES, J.A.S. Progresso genético e potencial de risco da cultura do sorgo granífero (Sorghum bicolor (L.) Moench) no Brasil. Piracicaba: ESALQ, 1990. 171p. Tese de Doutorado.

SAS INSTITUTE INC. SAS user's guide: statistics. 5.ed. Cary, NC, 1985. 956p.

SOARES, A.A. Desempenho do melhoramento genético do arroz de sequeiro e irrigado da década de oitenta em Minas Gerais. Lavras: ESAL, 1992. 188p. Tese de Doutorado.

TOLEDO, J.F.F.; ALMEIDA, L.A.; KIIHL, R.A.S.; MENOSSO, O.G. Ganho genético em soja no Estado do Paraná, via melhoramento. Pesquisa Agropecuária Brasileira, Brasília, v.25, n.1, p.89-94, jan. 1990.

VENCOVSKY, R.; MORAIS, A.R.; GARCIA, J.C.; TEIXEIRA, N.M. Progresso genético em vinte anos de melhoramento de milho no Brasil. In: CONGRESSO NACIONAL DE MILHO E SORGO, 16., 1986, Belo Horizonte. Anais... Sete Lagoas: EmbrapaCNPMS, 1988. p.300-306. 